\title{
The Effects of Captioned Slides on Learning of English Idiomatic Expressions among EFL Intermediate Learners
}

\section{Saeed Ketabi ${ }^{1}$, Ali Sadeghi*2}

${ }^{1}$ Department of English Language and Literature, Faculty of Foreign Languages, Isfahan University, Isfahan, Iran

2 Department of English Language, Faculty of Humanities, Islamic Azad University of Shahreza Branch, Shahreza, Iran

*Corresponding Author E-mail: ali.sadeghi2008@yahoo.com

Received: 15 December 2019, Revised: 23 January 2020, Accepted: 29 February 2020

\begin{abstract}
Using caption in teaching English as a second language has had its particular advocates throughout the history of language teaching. The present study intends to examine the potential effectiveness of captioned inputs for comprehension of English idiomatic expressions among EFL intermediate learners. It is set to determine how captioned inputs result in comprehension of English idiomatic expressions in comparison with noncaptioned inputs. To this end, the Oxford Placement Test (OPT) was administered to 82 students in an English Institute of Shahrekord, Iran, to find out their English proficiency levels. The participants took a test of 40 multiple-choice items as a pretest to determine their background knowledge in English idioms. The questionnaire data revealed that learners who used captions could promote their attention and improved their learning processing. A reliable posttest was administered after teaching fifteen units of their English textbook during 15 weeks. The mean score by Kolmogorov-Smirnov showed the group using captioned slides of English idiomatic expressions outperformed the other group.
\end{abstract}

Keywords: Captioning, Idiomatic Expressions, Captioned Inputs.

\section{Introduction}

As multimedia language learning materials are becoming increasingly common in foreign and second language classrooms, the design of those materials is becoming an important avenue of research in Computer-Assisted Language Learning (CALL). CALL is of interest to language teachers and learners because it can offer individualized instruction and immediate feedback on the correctness of a learner's reaction to computerized tasks (Nagata, 1993). Chappelle (2003) argues that the real challenge in applied linguistics at present is the search for "evidence for the most effective ways to design software for CALL, to use software effectively in tasks, and to help learners to take advantage of the electronic resources available to 
them". Technological tools such as television and computer are recognized as the most popular source of information and entertainment in the world. Caption is a kind of television or computerized program which connects the spoken language (audio form) with the written words (typing form) on the screen. It has become an integral part of television station operations which is broadly implemented in different parts of the world. Audiovisual materials improved with captions are powerful pedagogical tools that are believed to help L2 listening and reading comprehension skills (Borras and Lafayette, 1994; Danan, 2004; Garza, 1991; Markham and Peter, 2003). Captions facilitate language learning by helping learners visualize what they hear, especially if the input is slightly beyond their linguistic ability (Danan, 2004). Captions may also serve to increase language comprehension by facilitating additional cognitive processes, such as greater depth of spoken-word processing (Bird and Williams, 2002). Caption is a learning tool which accelerates the acquisition of communication and literacy skills. It stimulates word recognition and increases vocabulary, by providing video, audio and textual information to the student (Bird and Williams, 2002). Lewis and Jackson (2001) state that "Closed Captioning (CC) is an electronic process which converts the audio portion of a program into written words - like foreign language subtitles". Closed Captioning (CC) is typically displayed at the bottom of television and is not immediately visible but can be turned on through the television remote control or an external decoder. In contrast, Open Captioning (OP), like subtitle, is visible to all viewers and cannot be turned on while viewing a video (Gielen and d'Ydewalle, 1989). Captioning may be a benefit because it helps language learners connect auditory to visual input (Garza, 1991), which may aid form-meaning mapping, an essential process for foreign language acquisition (Doughty, 2004). Television viewers perceive the activity in the scenes, but when the specific visual information and subtleties of the conversation or narrative of the program are not evident, they are likely to misinterpret the intentions of the actions and meaning of the program. When access to relevant information is limited, comprehension is sacrificed. Captions with audiovisual materials are pertinent and fitted devices that assist to progress foreign language learners in L2 listening and reading comprehension skills (Borras and Lafayette, 1994; Danan, 2004; Garza, 1991; Markham and Peter, 2003). Using captioned videos can make learning English enjoyable and comfortable for students in learning situations. The purpose of the present study is to investigate the effects of captioned inputs for fruitful understanding of English idiomatic expressions among EFL learners in Iranian English classes.

\section{Statement of the Problem}

Most students do not overcome language learning problems and are not highly proficient enough to communicate fluently to use idioms in L2. Learners require engaging enthusiastically in processing the meanings of English idiomatic expressions they hear and read. A big problem in language teaching which our students encounter is that the tasks included in their textbooks do not give them enough practice in the idiomatic expressions they will need. In short, the textbooks somehow lack the variety of drills which can motivate and give learners a purpose for doing them. Although during recent years there have been some changes in English syllabuses at Iranian junior high schools 
and high schools, these changes have not always yielded positive results about learning the English idiomatic expressions. It seems that the designers were pretty honest in their attempts to take advantage of new findings in applied linguistics; they have always looked at English from a narrow point of view, i.e. as a designer, not from the point of view of the learners; therefore, the syllabuses designed were teacher-centered, not student-centered. Students' enthusiasm increases when they are exposed to their favorites. Captioning, as an educational tool, improves their grasp of idioms, slangs, lexicons and reading comprehensions. It may bring greater concentration for students to focus on the action of the program at the same time as watching the captions appearing at the bottom of the screen. Technological devices can eliminate the anxiety and confusion of teachers to teach English idiomatic expressions in educational settings. The new technology of captioning can give a hand to teachers to teach with a superior quality and with a quick speed.

\section{Purpose and Scope of the Study}

Students do not have common background knowledge of English idiomatic expressions. A lot of students are trained in rural areas in which un-qualified English teachers teach them while other students are taught in urban areas having access to a lot of classroom facilities to gain advantage of educational technologies. Some students take advantage of using satellite programs, VCD and video tapes, and go to private language schools, whereas most of them just have their textbooks as the only source of educational program. Accordingly, the purpose of this study is to set up a proper ground for the educational system in order to help English teachers teach their students by means of the computerized systems and utilize innovative techniques for teaching English idiomatic expressions. Captioning technology would flourish as a suitable and a helpful accessory for English teachers which can promote pedagogical syllabuses and learning strategies in Iranian English institutes. These researchers examine the productive effects of captioned slides for teaching English idiomatic expressions in English learning situations.

\section{Research Questions and Hypotheses}

Teachers need to use new ways to prepare the students to take part actively in learning situation in order to achieve the goal; i.e. communication. As a result, the following research questions will direct the present study:

1. Do English captioned inputs result in better comprehension of English idiomatic expressions in comparison with noncaptioned inputs?

2. Do proficiency levels differentiate the EFL learners' comprehension of English idiomatic expressions through captioned inputs?

Accordingly, the hypotheses under investigation would take the following forms:

Ho: There is no meaningful relationship between captioned inputs and a long-term comprehension of English idiomatic expressions.

H1: There is a positive relationship between captioned inputs and a long-term comprehension of English idiomatic expressions.

\section{Significance of the Study}

Idiomatic expressions, frequently used by languages in the world, mostly have sociocultural, historical, or political origins. Although many similar expressions can be 
found across languages, many more do not coincide exactly in their linguistic or semantic meaning and use (Laufer, 2000; Liontas, 2001; Zarei and Koosha, 2003). Idiomatic usage is so common that it can be difficult to speak and write without using idioms (Seidl and McMordie, 1978). Since idioms are frequently utilized in spoken and written English, language learners must make an effort to master idioms, though complete mastery may be nearly impossible (Cooper, 1999; Irujo, 1986; McCarthy et al., 2010). Because English is so highly idiomatic and figurative, idiomatic expressions make up the heart of the language, giving it color, feeling, charm, and precision (Adkins, 1968). Idioms are generally a pervasive feature of many languages and English particularly seems to be rich in such multiword lexemes (Goulden and Read, 1990). Therefore, being competent in understanding and using idioms is in fact paramount to having a good command of the depth of vocabulary (Milton, 2009). Also, knowledge of idioms correlates highly with vocabulary span (McGavigan, 2009). This study investigates how captioned inputs can lead Iranian EFL learners to acquire English idiomatic expressions proficiently. There are a large number of schools, English institutes, and English laboratories where learners are going to learn English to meet their requirements. Thus, the most remarkable part of their daily conversations depends on English idiomatic expressions which are mainly used in their exchange of their ideas. This technology can help them to learn the idiomatic expressions more efficiently. On the other hand, computerization of expressions can refresh the leaner's mind and reduce the affective filter of students. Captioning can also develop the sphere of influence of vocabulary for students and involve them in learning the idiomatic expressions, to connect the written form of the language with the verbal form and to promote expression, verbal phrasing, and pronunciation. Caption program can be used to many Iranian English learners, especially intermediate and advanced students, to learn more idioms due to the fact that these learners have had a good exposure to the target language and have learnt to appreciate the value and the importance of idioms, including their vividness and effectiveness in communicative tasks.

\section{Literature of Review}

On August 5, 1972, Julia Child, "The French Chef," in a program televised from WGBH studios in Boston, taught viewers how to make one of her prized chicken recipes. The significance of that day stretched far beyond the details of the entrée to have a profound and lasting impact on human communication (Greg Wordy, 1972). Captioning was introduced in Canada in 1980 to provide access to television for the deaf and hard of hearing problem. Educators have begun to investigate the use of closed captioning television (CCTV) as a language and literacy learning tool and the potential uses of CCTV in teaching reading to members of the hearing community have been commissioned by organizations such as VA, and the Caption Center in Boston, MA (Bean and Wilson, 1989). Studies also report the motivating influence of captioned television, and extremely positive attitudes on the part of students toward this medium (Bean and Wilson, 1989). The use of CCTV with high school ESL students and students in corrective reading programs increased the students' motivation, and resulted in an improvement in their English vocabulary, reading comprehension, and word analysis skills (Goldman and Goldman, 1988). 
Other studies confirm the benefits of captioned programming and films for nonnative English speaking and students, such as: Koskinen et al., (1996). It was believed that it can enhance the learners' attention, reduce the confusion and anxiety, decrease affective filter, give permanent stability of their understanding and increase their motivation (Froehlich, 1988; Grimmer, 1992; Vanderplank, 1988). The general compromise was that captioning leads to greater performance on ongoing listening comprehension. One of the most important experiments along this line was conducted by Bird and Williams (2002), who investigated that captioning is a constructive language learning device by looking at how a bimodal presentation (aural and visual) of key words would affect the learning of the words positively. In their study, vocabulary was presented to advanced learners of English fewer than three conditions: (a) text with sound, (b) text without sound, and (c) sound without text. Bird and Williams considered the effects of these conditions on word learning, and recognition memory. The findings showed presentation of vocabulary through text and sound resulted in further recognition memory for spoken words and non-words when compared to text without sound and sound without text. Markham (1993) found that captions were more useful to advanced learners when the video issues were more abstract or sophisticated. He investigated that learners from intermediate to advanced levels could comprehend the difficult materials with. Guillory (1998) also found that captions were useful for beginning-level learners. She found that beginning-level students benefit more when only key words were presented as captions, not entire sentences presented on screen. Vanderplank (1990) examined how learners of English used captions over a three-month period. Those who took notes while watching captioned videos produced more accurate language on successive comprehension exercises. Those who did not take notes comprehended as well as the note-taking group, but did not keep specific language used in the videos. Vanderplank (1990) concluded that attention (form-focused) and processing (meaning-focused) are important for the intake and long-term retention of forms through captions. Danan (2004) reviewed the benefits and limitations of audiovisual materials and strategies that might optimize the use of captioned material. She suggested that researchers look at more successful language learners as models because they are able to process information through captions. In Web and computer-based multimedia environments, learners and teachers can change captions on or off. Markham (2001) investigated whether the potential presence of captions affects learning. Familiarity with the content of the video affects the effectiveness of captions. His results revealed that both background knowledge and captions contributed largely to the learners' comprehension of the videos. Grgurović and Hegelheimer (2007) conducted an empirical study to explore whether captions or transcripts were more effective in a multimedia video environment. They found that students who used captions used them more frequently and for longer periods of time than those who used transcripts. Pujola (2002) researched the strategies used by Spanish-speaking ESL learners who used Web-based multimedia videos. She tracked whether the learners chose to use captions or transcripts when watching videos and found that those with poorer listening skills used captions and transcripts more for help with comprehension. Pujola (2002) found 
that some learners based their listening comprehension on reading instead of listening. She stressed that this "misuse" of captions can potentially inhibit the development of listening strategies, and explained that students need to be advised when to use captions. According to Welles (2004), many educational settings are eager to use online foreign language course offerings, commonly by implementing hybrid or blended-instruction courses, in which part of the instruction is in the classroom and part is conducted independently online. Such classes integrate more online and computerized content, which often includes captioned videos. It is mainly true for language programs such as Chinese and Arabic, since it is extremely difficult to achieve pretty qualified teachers to teach them (Dahbi, 2004; Freedman, 2004), and because videos are a good resource for presenting native speaker voices. Captioning can aid language learners to connect audible and visual input, which may help to establish form-meaning mapping, a fundamental process for foreign language acquisition (Doughty, 2004). With regard to the study, the form-meaning mapping is facilitated since captioning helps learners to determine word boundaries in the utterances. On the other hand, it helps learners to find out the stream of speech produced by speaker. It is a powerful instructional tool known to have a motivational, attentional, and affective impact on viewers, which in turn facilitates auditory processing (Baltova, 1994). Gass (2005), Sydorenko and Winke (2010) investigated the effects of captioning during video-based listening activities. The results revealed that learners used captions to increase their attention, improve processing, reinforce previous knowledge, and analyze language. To sum up, the present study investigates the effectiveness of captioned slides on the Persian students' comprehension applying English idiomatic expressions in English classroom or out-ofclass activities.

\section{Theoretical Framework}

The interactions theory of SLA considers interaction to be a significant factor for language acquisition since it can promote negotiation of meaning (Long, 1996; Pica, 1994). Although originally based on the study of the negotiation of meaning between human interlocutors, the notion of interaction in Computer Assisted-Language Learning (CALL) was extended to include person-computer interaction during a task completion (Chapelle, 2001). A key component of this theory-that only the input that is noticed, or apperceived, can become beneficial-provides guidance for the design of instructional materials, which should contain some captioned inputs for the English learners to get the higher knowledge of English skills.

\section{Materials and methods}

\section{Participants}

The participants were 82 Persian EFL female learners in the intermediate level. They studied in Andisheh Farda English Institute in Shahrekord, Iran, with the age range of 15 to 20 . The selection was on the basis of random sampling from the general population. Participants randomly assigned to two groups in the treatment.

Table1. Information of Participants

\section{Mother's Language} Persian
No of CG. (1)

41
No of EG. (2)

41
Sexism

Female
Average age

15-20 


\section{Instrumentations Oxford Placement Test (OPT)}

The Oxford Placement Test was administered to categorize participants into the "higher" and "lower" levels of English proficiency.

\section{Pre-test}

A reliable recognition test of English idiomatic expressions including 40 item multiple-choice tests was administered as a pre-test. The allotted time to answer the questions was thirty minutes. The answer sheets were scored by the researcher and the correct choices gained one point and wrong parts got zero. There was no penalty for wrong choices.

\section{Closed-item Questionnaire}

The questionnaire included some statements and questions of which followed by Yes/No alternatives. It essentially asked general questions relating to the usefulness of captions to teach idioms. The researcher asked participants about their experiences while watching the slides and what they did when the captions were presented on screen.

\section{Slides}

Slides were prepared from the English idiomatic textbook "Can You Believe It?" Stories and Idioms from Real Life Book (1) written by Jann Huizenga (1997). The researchers selected the English idiomatic expressions from this book which were quite relevant to the participants' learning experience in harmony with their English proficiency. The textbook presented the origins of more than 100 idiomatic expressions, so it served as an appropriate reference for the purpose of the study. Targeted language captions of English idiomatic expressions were added to the slides to be displayed by PowerPoint software on a computerized system. To show the program, the computer was linked to the Over Head Projector (OHP) to magnify the screen in front of the classroom. The first slides, with captioning, presented with audiovisual and textual along with English idiomatic expression viewed only for group (A). The second type of slides followed the audile program displayed for group (B) and did not have any choice to use captionedbased idiomatic expressions on the screen. Slides included fifteen units of the textbook and dealt with common American English idiomatic expressions utilized in their everyday conversations. Each captioned slide and without caption, approximately 3-5 minutes in length, had a native narrator who described the scene and told the story.

\section{Post-test}

At the end of the experiment, a posttest containing the forty idioms taught during the treatment period was given to the participants. The participants were supposed to choose the correct idiom among the four alternatives. The allotted time was thirty minutes and finally the test was objectively scored by the second researcher. There was one point for each correct answer and zero for wrong answers. There was no penalty for wrong answers.

\section{Procedure}

The study took place in English Institute of Andisheh Farda in Shahrekord equipped with computerized facilities. Participants took the Oxford Placement Test (OPT) to classify them in high and low levels of English proficiency. The selected levels of participants were divided in two equal groups. In other words, all of participants 
with low and high levels of English proficiency were equally distributed in two groups by the researcher. To measure the English background knowledge of participants, a 40-item multiple choice pre-test of idiomatic expressions was administrated at the outset of the term. The pre-test was administered in an identical situation for both groups. The instructor taught the selected textbook according to captioned-based slides and non-captioned slides. Slides were appeared with pop-on captioning type with a phrase or sentence all at once -not line by line, stayed on the screen for a few seconds with the targeted picture and related soundtrack narrated by a native speaker then disappeared or replaced by another one. Slides with captioning contained English idiomatic expression texts appeared at the bottom of the screen for a few seconds, then another slide replaced by a full caption. Captions were timed to synchronize with the program and placed on the screen to help the speaker. They were prerecorded by the researcher with the Power point software and usually one and two lines of the texts were visible for several seconds before they disappeared. Each slide approximately portrayed six to seven English idiomatic expressions of the textbook. Each slide (captioning and without captioning) was played twice for experimental and control group. The experimental group watched slides with audible and visual program along with captioned idiomatic expressions. The control group merely listened to audible part without any pictorial and captioning program. The subjects filled out a closedtype questionnaire, followed by a presentation explaining so as to clarify whether they were familiar with targeted idioms or not. The statements and questions of questionnaire were Yes/No alternatives which participants respond them in every session. After teaching each unit, participants were engaged in different classroom tasks/activities to do the exercises. Exercises included matching, multiple-choice, fill in the blanks, short answers and retelling the story. All the activities were according to a lesson plan prepared by the teacher in every session. All groups enjoyed the same constructional environment and ad ministerial conditions. At the end of the term, a 40-item multiple-choice test was administrated to two groups as a post-test to evaluate the findings of the study. The procedure lasted for 15 weeks in a term.

\section{Results and discussion}

\section{Analysis of the Students' Score on the Pre-test}

The experimental group and the control group achieved similar scores on the pretest. The mean for the control group ( $\mathrm{n}$ $=41$ ) on the pre-test was 25.85 out of a possible 40 (64.62\%), and the standard deviation was 2.87. Table 4.1. shows the results.

Table 4.1. Descriptive Statistics for the Pre-Test of Control Group

\begin{tabular}{|c|c|c|c|c|c|c|c|}
\hline & $\mathrm{N}$ & Minimum & Maximum & \multicolumn{2}{|c|}{ Mean } & Std. Deviation & Variance \\
\hline & Statistic & Statistic & Statistic & Statistic & Std. Error & Statistic & Statistic \\
\hline $\begin{array}{l}\text { Pre-test of } \\
\text { control group }\end{array}$ & 41 & 21.00 & 34.00 & 25.8537 & .44934 & 2.87716 & 8.278 \\
\hline $\begin{array}{c}\text { Valid N } \\
\text { (listwise) }\end{array}$ & 41 & & & & & & \\
\hline
\end{tabular}


For the experimental group $(\mathrm{n}=41)$ on the the standard deviation was 3.55. Table 4.2. pre-test, the mean was 26.48 (66.2\%), and shows the findings.

Table 4.2. Descriptive Statistics for the Pre-Test of Experimental Group

\begin{tabular}{|c|c|c|c|c|c|c|c|}
\hline & \multirow{2}{*}{$\begin{array}{c}\mathrm{N} \\
\text { Statistic }\end{array}$} & \multirow{2}{*}{$\begin{array}{c}\text { Minimum } \\
\text { Statistic }\end{array}$} & \multirow{2}{*}{$\begin{array}{c}\text { Maximum } \\
\text { Statistic }\end{array}$} & \multicolumn{2}{|c|}{ Mean } & \multirow{2}{*}{$\begin{array}{c}\text { Std. } \\
\text { Deviation } \\
\text { Statistic }\end{array}$} & \multirow{2}{*}{$\begin{array}{c}\text { Varianc } \\
\text { e } \\
\text { Statistic }\end{array}$} \\
\hline & & & & Statistic & Std. Error & & \\
\hline $\begin{array}{l}\text { Pre-test of } \\
\text { experimental } \\
\text { group }\end{array}$ & 41 & 20.00 & 34.00 & 26.4878 & .55450 & 3.55051 & 12.606 \\
\hline $\begin{array}{c}\text { Valid N } \\
\text { (listwise) }\end{array}$ & 41 & & & & & & \\
\hline
\end{tabular}

\section{Analysis of the Students' Score on the Post-test}

The results obtained revealed from the control group did not show significant difference, that is, the control group did not significantly outperform the The retention of the idioms was evaluated through a posttest containing the idioms taught during the treatment. The results obtained revealed that the experimental group performed significantly better than comparison group with regard to comprehension of the idioms. The mean for the control group on the post-test was 26.39 out of a possible $40(65.97 \%)$, and the standard deviation was 3.19. These figures are summarized in Table 4.3.

the comparison group. For the experimental group, the mean was 29.04 $(72.60 \%)$ and the standard deviation was 3.58. Table 4.4. shows the figures.

Table 4.3. Descriptive Statistics for the Posttest of Control Group

\begin{tabular}{ccccccccc}
\hline & & & & & & \multicolumn{2}{c}{$\begin{array}{c}\text { Std. } \\
\text { Narianc }\end{array}$} \\
& Statistic & Minimum & Maximum & \multicolumn{2}{c}{ Mean } & \multicolumn{1}{c}{ Deviation } & e \\
\hline $\begin{array}{c}\text { Posttest of } \\
\text { control group }\end{array}$ & 41 & 19.00 & 34.00 & 26.3902 & .49863 & 3.19279 & 10.194 \\
Valid N (listwise) & 41 & & & & & & \\
\hline
\end{tabular}

Table 4.4. Descriptive statistics for the posttest of Experimental Group

\begin{tabular}{|c|c|c|c|c|c|c|c|}
\hline & $\mathbf{N}$ & Minimum & Maximum & & Iean & $\begin{array}{c}\text { Std. } \\
\text { Deviation }\end{array}$ & $\begin{array}{c}\text { Varianc } \\
\text { e }\end{array}$ \\
\hline & Statistic & Statistic & Statistic & Statistic & Std. Error & Statistic & Statistic \\
\hline $\begin{array}{l}\text { Posttest of } \\
\text { experimental } \\
\text { group }\end{array}$ & 41 & 23.00 & 36.00 & 29.0488 & .55978 & 3.58435 & 12.848 \\
\hline Valid N (listwise) & 41 & & & & & & \\
\hline
\end{tabular}

Descriptive statistics for each of the individual items were also computed, and the item facility values and corrected itemtotal correlations were examined in order to investigate how each item performed. All 40 items were deemed acceptable to use in subsequent analyses. 


\section{Answers to the Research Questions}

To assess and judge the effects of the treatment by the difference between the pretest and posttest scores and finding the answers of research questions, a 40-item multiple-choice test was administered as the pretest of the study. The pretest was applied and the mean scores between control and experimental groups were compared. At the end of the study, a post-test was administered to disclose the effect of the treatment.

\section{Answer to the Research Question1}

The results from Tables 4.2. and 4.4 are used to answer our research question: Do English captioned inputs result in better comprehension of English idiomatic expressions in comparison to non-captioned inputs?. The group that included learners who viewed the slides twice, both times with captions performed significantly higher on the English idiomatic expressions than those who saw the slides without captions both times according to means of pre-test and posttest. Mean of pre-test in experimental group is 26.48 and mean of posttest in experimental group is 29.04. Therefore, watching the slides with captions both times resulted in significantly higher scores than watching without captions both times. According to Tables 4.1. and 4.3. the mean on pre-test in control group is 25.85 and in the posttest are 26.39. There is a discrepancy between the means of the two groups. In line with these results, captions both times also resulted in

Table.4.5. One-Sample Kolmogorov-Smirnov Test of Control Group

\begin{tabular}{ccc}
\hline & & Percent \\
\hline Normal & $\mathbf{N}$ & $\mathbf{4 1}$ \\
Parameters & Mean & 25.8537 \\
Most & Std. Deviation & 2.87716 \\
Extreme & Absolute & .130 \\
Differences & Positive & .130 \\
& Negative & -.115 \\
& Kolmogorov-Smirnov Z & .834 \\
& Asymp. Sig. (2-tailed) & .490 \\
\hline
\end{tabular}

significantly higher comprehension of English idiomatic expressions than no captions.

\section{Answer to the Research Question 2}

The second research question was:Do proficiency levels differentiate the EFL learners' comprehension of English idiomatic expressions through captioned inputs?. It was found that all language learners in different proficiency levels performed more effectively. The lower-level learners and upper-level learners in experimental and control groups had an identical opportunity and conditions to learn the English idiomatic expressions. It was not highlighted that the upper-level learners attained the highest scores in pre-test and posttest. This study reported that proficiency differences did not affect any benefits derived from captions regardless of year of study. This may suggest that captioning, as a language learning tool to aid processing, may function similarly for all proficiency levels. Concerns about whether lower-level students can benefit from captions in the same way as upper-level learners do (Guillory, 1998; Markham, 1993) may be more about the appropriateness of the slide's complexity level for the lower-level learners rather than the appropriateness of the captioning for lowerlevel learners. 
Test distribution is Normal

Table 4.5 shows that the Asymp. Sig. (2tailed) for control group on the pre-test is 0.49 and greater than 0.05 . Therefore, the variables are normally distributed and assumption is that neither of the two sets of scores is skewed. Furthermore, as Table
5.6 reveals, the Asymp. Sig. (2-tailed) for experimental group on the pre-test is 0.53 and is greater than 0.05 . Therefore, the variables are normally distributed and assumption is that neither of the two sets of score is skewed.

Table.4.6. One-Sample Kolmogorov-Smirnov Test of Experimental Group

\begin{tabular}{ccc}
\hline & & preexp \\
Normal & $\mathbf{N}$ & $\mathbf{4 1}$ \\
Parameters & Mean & 26.4878 \\
Most & Std. Deviation & 3.55051 \\
Extreme & Absolute & .126 \\
Differences & Positive & .126 \\
& Negative & -.094 \\
& Kolmogorov-Smirnov Z & .804 \\
& Asymp. Sig. (2-tailed) & .538 \\
\hline
\end{tabular}

The Homogeneity of Variances in PreTest

The assumption of homogeneity of variances apparently had the effect on the groups. Since Sig. (2-tailed) is 0.377 and is greater than 0.05 , the research results of variances in two groups are not varied and had an identical balance. As a result, the mean of the scores of pre-test of two groups are equal $\left(m_{1}=m_{2}\right)$, and it could be possible to compare the variables in posttests. Table 4.7. shows the results.

Table.4.7. Independent Sample Test for Pre-test of Control and Experimental Groups

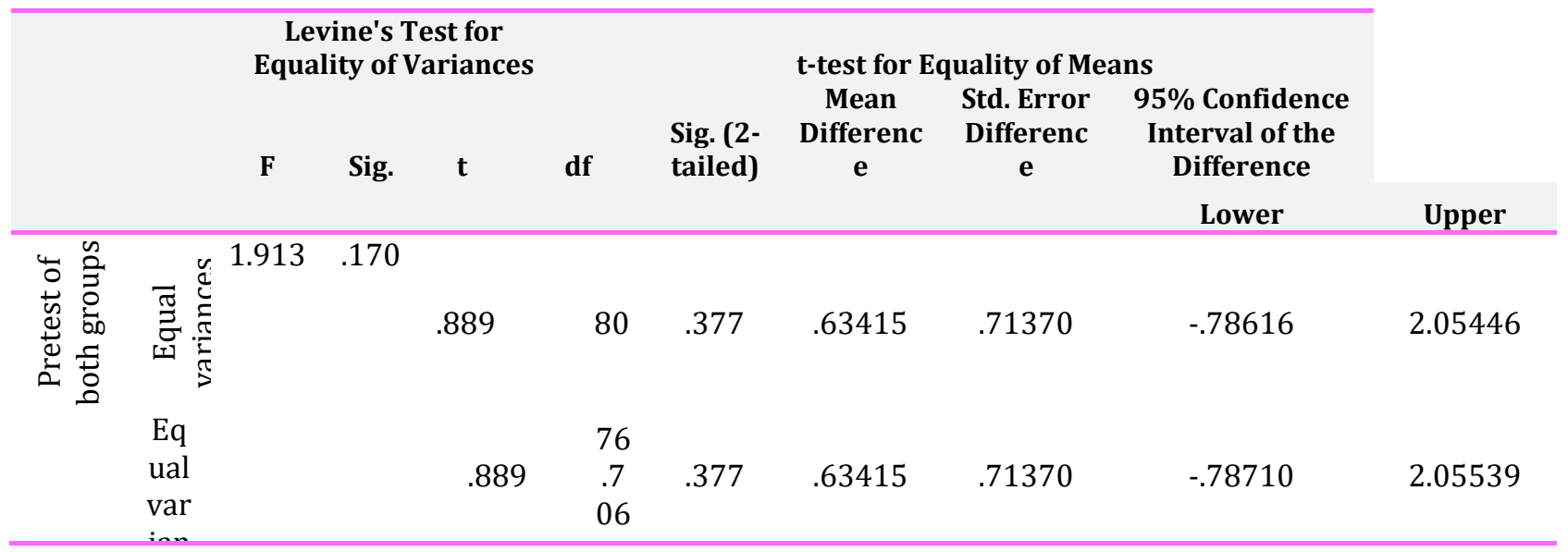




\section{Checking the Hypotheses of the Study}

The central question underlying the research hypothesis was to observe frequencies for the different categories within the variables are related or independent. To test the hypotheses, the researcher formulated the research hypotheses as following:

H1: There is a positive relationship between captioned inputs and a long-term comprehension of English idiomatic expressions.

Ho: There is no meaningful relationship between captioned inputs and a long-term comprehension of English idiomatic expressions.

The null hypothesis $\left(\mathrm{H}_{0}\right)$ is rejected and the alternative hypothesis $\left(\mathrm{H}_{1}\right)$ is accepted, because the value of sig is greater than 0.05 and variances of variables were equal and the sig (2-tailed) is less than 0.05 . There is a meaningful and significant relationship between variables while $\mathrm{M}_{1}$ (the mean of control group) is not equal with $\mathrm{M}_{2}$ (the mean of video group). Finally, the difference between means of both groups in control and experimental group is less than zero $\left(\mathrm{M}_{1}-\mathrm{M}_{2}<0\right)$. Consequently, the mean of control group is less than the mean of experimental group $\left(\mathrm{M}_{1}<\mathrm{M}_{2}\right)$. According to above statistical logic, there was a positive relationship between the learners' performance with the treatment (captioned slides).

\section{Discussion}

This study set out to investigate how Iranian English learners deal with English idiomatic expressions through captioned slides in English classes. By presenting captioned and non-captioned slides to groups of Persian English learners, the researcher captured, in response to the first research question, captioned rather than non-captioned slides aid learners to understand English idiomatic comprehension and recognition more easily and more effectively. Captioned slides also aid overall comprehension of the English texts. In other words, the use of different modalities (combination of English texts with musical apparatus) appeared to facilitate idiomatic expressions in recognition and overall comprehension. The advantage of multiple input modalities is supported by previous research, such as Winke et al, (2010) who found that captioning was more effective than no captioning, stating that captioning during the showing of the videos was more effective for performance on aural vocabulary tests. Also, Bird and Williams (2002) found that a bimodal presentation (in their case, text and sound) resulted in better recognition memory. According to Dornyei (2005), it appears that more input is more effective, leading to increased depth of processing since learners utilize different input modes differently, and these input modes stimulate one another. It is understandable that individual learners may be able to process one mode of input better than another. Winke et al, (2010) noted, learners interact differently with the environment and approach learning tasks differently and captioned video allows this to happen. Many of participants' comments indicated that the captions served the function of drawing learners' attention to the language in the slide. The captions seemed to help isolate what the learners perceived to be important and helped them determine what to pay attention to in subsequent viewings. With regard to attention, it is well documented that language learners are often faced with a string of sometimes incomprehensible input and need to focus attention on 
particular parts of language as aspects of the learning process. In fact, Schmidt (2001) claims that attending to particular parts of language "appears necessary for understanding nearly every aspect of second and foreign language learning" ( $p$. 6). This claim is integral to Schmidt's (1990, 1993, 1994, 1995, 2001) noticing hypothesis: awareness (through attention) is necessary for noticing, which in turn is essential for learning. In a similar vein, Gass (1997) argued that interaction often serves as a priming device, setting the stage for learning rather than being a forum for actual learning. The same may be the case for captioning. When captioning occurs first, it may draw learners' attention to something they do not know. This allows for further information-gathering process during the second language learning. This is easier for those who can easily read the script. Reading an unknown script requires more prior knowledge, which in this case comes from hearing the unknown idioms. In other words, with scripts that are similar to the native language script, it is easier to be alerted to something unknown through seeing it in writing; with scripts that are different from the native language script, it is easier to be alerted to something unknown through hearing it spoken. Acquisition does not necessarily happen immediately; it takes time and often requires repeated input, especially when the input comes through multiple modalities.

\section{Discussion}

According to the results of the study, the mean of two groups in pre-test and posttest was significantly different. It showed that the Persian EFL learners outperformed with captioned slides for comprehension of English idiomatic expressions. The proficiency levels of students did not have a salient effect on learning the idioms. The findings of this study to address the first research question, whether English captioned inputs result in better comprehension of English idiomatic expressions in comparison to non-captioned inputs, are in line with those of Winke et al, (2010) who found that learners who saw the videos with captions performed significantly higher on the vocabulary test with written input than those who saw the videos without captions. Learners who used captioned slides outperformed those who did not use captioned program. It was also revealed that the participants in different levels can get the targeted purpose of the study and there was not any important difference.

\section{Conclusion}

This research provides strong evidence that captioned input has beneficial effects on the long-term comprehension of English idiomatic expressions in the intermediate level of Iranian EFL students. The significant outcome of the effects of captioning on the subscales vocabulary/phrase acquisition and general comprehension-is clearly consistent with the results of previous studies, such as the work of Neuman and Koskinen (1992) and Adler and Goldman (1988). Students' attitude toward L2 learning by captioning also is consistent with the previous research of Koskinen et al., (1996). It has produced a number of observations about the use of captions, confirming previous research indicates that captions are useful because they result in greater depth of processing by focusing attention, reinforce the acquisition of idiomatic expressions through multiple modalities, and allow learners to determine meaning through making easier of language chunks. The researcher found that captioned slides 
may reduce the learner anxiety and promote the automaticity in processing. The study found the results harmonized with Parks (1986) urging suitability and familiarity of subject matter regarded totally for the level of proficiency of both groups. The study paved the way for preparing some controllable tasks that were appropriate for students' ability levels. They could promote active and full participation of students and could control the length of the lesson to ensure maximum concentration and interest. They also provided students with opportunities to operate the class activities, and review the English idioms. Proficiency differences were not found to affect any benefits derived from captions. This may suggest that captioning, as a language learning tool to aid processing, may function similarly for all proficiency levels. Thus, it appears that captions are beneficial for all of proficiency levels, as long as the slides are matched appropriately in terms of content and complexity (not too hard and not too easy) to the proficiency level of the language learners. The researchers found that students were attracted to the captioned technology. They paid rapt attention to the screen and worked hard to decipher the language. They spontaneously wrote down the unknown words they saw on the screen. Thus, the captions enabled students to identify the written forms of familiar vocabulary, and reinforced the meaning in an audio and slide format. Students often repeated phrases from the captions over and over to themselves while watching. On subsequent viewing of a program, they paid greater attention to the captions, anticipating the spoken text by saying the phrase aloud as soon as it appeared on the screen, even before it was spoken on the audio track. In addition, students used vocabulary from the program in follow-up discussions and written exercises. Furthermore, since culture-bound expressions are unique to any language, they require an adequate cultural awareness of both source and target languages (e.g. American/British English and Persian in the study), and they cannot be understood just from the meaning of their individual words. Captioned program could transform the cultural points of the targeted language. The learners not only learned the idiomatic expressions but also, in line with Smith (2004), concluded that captioning transforms the seductive medium of culture. It is a language learning tool and helps newcomers to provide them an important conveyor of culture and information. Smith warns, however, that care must be taken in identifying suitable programming. Students approach programs with varying degrees of linguistic proficiency and familiarity with the cultural contexts involved.

The researchers found that learners pronounce the idiomatic expressions part by part as watching the slides. When the captioned slides appeared on the screen, students involved themselves to isolate the idiomatic expression from the whole text. Therefore, in agreement with Ellis (2003) who stressed that "learning to understand a language involves parsing the speech stream into chunks which reliably mark meaning", the researchers believed that captions help learners see and be able to then parse structural patterns or chunks in the captioned slides, which may assist them in remembering and learning from the patterns presented. In accordance with participants' comments, captions can be a crutch. The "crutch" notion is a positive one in that when learners do not have to focus on extracting meaning from the sounds they hear, they can focus on the form and link that form to meaning. 
Learning requires learners to actively attend to L2 forms in order for learning to take place. Although the experimental group heard the narration of captioning, they paid much attention to the text displayed at the bottom of the screen. They made a link between the form of idiomatic expression they heard and the meaning of the sentences watched by captioning. It was evident that some listening parts were beyond the students' abilities to comprehend well. But, at times, the language input (in this case the captioned slides) was a necessary section for learners to have additional help, as found by Markham (1993). In this sense, captions can be a sort of scaffold or tool to aid L2 learning. By effectively utilizing the technology of captioned input in a classroom setting, students could advance their literacy levels through exposure to English vocabulary and syntax (Whitehurst and Lonigan, 1998). Students could preview and discussed the script with the teacher to highlight areas in which students lacked knowledge about concepts used in the captioned medium. In addition, teacher could work on reading comprehension skills by having students recall the scenes in the slides; words that have multiple meanings could be revealed by the actions or scenes. Because captioning program was not a fixed media (such as illustrated book), it might provide additional information to viewers, captions were a form of aiding technology by designed to promote functional abilities of viewers who were unable to achieve the audio portion of a program. Reading captions was equivalent to reading a printed script, and viewers comprehended the script.

\section{Implications}

The findings from this study provided further empirical evidence strengthening claims about the pedagogical use of captioned technique for English improvement. Participants in the treatment group significantly improved their perception of idiomatic expressions and their production of idiomatic expressions with limited exposure to the available treatment. It might be argued that participants in the treatment group merely improved their familiarity with the procedure and format for producing idioms. For language instructors who do not feel comfortable teaching idioms or who cannot fit it into their curriculum, computer-assisted program can provide an effective way to help students improve their ability to perceive, predict, and produce idiomatic expressions outside of class. Another implication is based on recommendations for change given by the treatment participants. Students may be more motivated to complete computerassisted tasks if the tasks are available for them to do at a time and in a location of their choosing. In this study, participants were required to complete the tasks in class which were controlled by the teacher. The importance of idioms and applying them in daily conversations is completely evident to every English speaker. This aspect of language is mostly ignored in Iran's pedagogical system and many EFL learners in Iran have problem with. The current study tried firstly to open a new way for EFL learners to learn and apply the potential usefulness of idioms into language classrooms and secondly how teaching of them could cope with this technology. The participants were Iranian EFL learners who had not access to a native speaker as a teacher. In other words, it was assumed that teaching idiomatic expressions through captioning would be more effective.

\section{Theoretical Implications}


Learning to listen for global meaning in the target language is a valuable skill that students learn from caption. The problem faced by the students in learning idioms is that even they see their forms but they have difficulties in their meanings. Captioning helps them to overcome that problem and gain confidence in their ability to guess the meaning from the target language that they watch. Another valuable aspect that the students learn from caption is that it helps them sharpen their writing and spelling. They are encouraged to use visual memory and clues to make themselves familiarize with daily colloquial language. The researchers believe that captioning can be a competent candidate to accompanying all language skills and an inseparable part of future class activity since the students embrace it as an accessory in learning English.

\section{Practical Implications}

The findings of this study have some implications for English teachers at school and institutes to use caption as a technique for teaching as well as testing language more effectively. They can also make use of it on working the language skills and sub skills. The findings invite the teachers and scholars to renew the methods of teaching and update those exercises to be used in language teaching. Because the study found that caption can have a positive effect on listening comprehension ability of the intermediate students, EFL teachers can use it with more confidence in the classrooms. In some countries such as Iran which students do not have access to the native English speakers, EFL teachers can make use of this technique to familiarize their students with the English spoken by the native speakers. If EFL students are exposed only to spoken English by Iranian EFL teachers, even after learning considerable grammar and vocabulary and in particular idiomatic expressions they cannot understand native English speakers easily. Thanks to the shown idioms at the bottom of the screen for the students, it would promote the better understanding of word and phrase pronunciation. It would also help learners to speed up reading skill by chunking and phrase by phrase. Exposure of the material opens a new framework for students to amuse themselves overall the term.

\section{Limitations of the Study}

The major limitation of the current study was the fact that it explored only group performance, rather than individual learner performance. While the evidence presented in this study is informative in suggesting how the non-verbal components of captioned programs might lead to increase L2 proficiency, future studies are needed to investigate how English learners vary in their ability to utilize captioning to firstly comprehend the text and then learn it, and how this varying ability might affect the learner's performance. Another shortage of the study related to the pre-test for both groups was quite capable considered as an intervening variable since they had a practice effect of the scores of the students on the posttest. Another limitation of the study was that there was not a good deal of equipped language institutes in Iran to apply different modalities to expose the targeted inputs. The last limitation to be mentioned here relates to the facilities such as computer system and Over Head Projector (OHP) needed to conduct such research. Any distraction from the environment may change the participant's focus of attention and result in some unintentional interruptions which in turn affect the findings of the study. The participants' ability to comprehend and 
remember the meaning of idioms does not necessarily mean that they will be able to correctly use them in productive skills. After all, it should not be forgotten that the ultimate goal of language learning is communication. Therefore, further studies need to be done to measure the students' ability to naturally produce idioms learned through communication.

\section{Suggestions for Further Study}

Future research should address a number of additional questions pertaining to the use of captions. How precisely are English learners focusing on while watching caption? Do upper-level learners ignore captions more often than lower-level ones? What are the individual differences that contribute to learners' utilization of captions, such as use of learning strategies, modality preferences, and memory? Do additional viewings of a video with captions result in greater vocabulary and comprehension gains, or is there a ceiling effect? Can teachers teach learners how to use captions effectively? Can captioned movies or shows help learners as a selfstudy source for learning at home? Is caption an effective aiding instrument for impaired children when they are being taught? In which cognitive domain of learning can caption be more effective? Can captioning be an effective modality for male gender?

\section{References}

Adkins, P. (1968). Teaching idioms and figures of speech to non-native speakers, Modern Language Journal, 52:148-152.

Adler, B. (1988). Using Closed Captioned Television in the Classroom: New Directions, in Reading: Research and Practice, University of Maryland, College Park, Maryland, pp. 11-18, 1985.
Bird, S. A, Williams, J. N. (2002). The effect of bimodal input on implicit and explicit memory: An investigation into the benefits of within-language subtitling. Applied Psycholinguistics, 23(4): 509-533.

Borras, I, Lafayette, R. C. (1994). Effect of multimedia courseware subtitling on the speaking performance of college students of French, The Modern Language Journal, 78(1): 61-75.

Chapelle, C. A. (2001). Computer applications in second language acquisition: found ations or teaching, testing, and research, Cambridge: Cambridge University Press.

Cooper, T. C. (1999). Processing of idioms by L2 learners of English, TESOL Quarterly, 33: 233-262.

Cutting, J. C, Bock, K. (1997). That's the way the cookie bounces: Syntactic and Semantic components of experimentally elicited idiom blends, Memory and Cognition, 25(1):57-71.

Borras, I, Lafayette, R. C. (1994). Effect of multimedia courseware subtitling on the speaking performance of college students of French, The Modern Language Journal, 78: 61-75.

Dahbi, M. (2004). English and Arabic after 9/11, The Modern Language Journal, 88(4):628-630.

Danan, M. (2004). Captioning and subtitling: Undervalued language learning strategies, Meta, 49(1): 67-77.

Ellis, N. C. (2003). Constructions, chunking, and connectionism: The emergence of second language structure. In C. J. Doughty and M. H. Long (Eds.), The handbook of second language acquisition, New Jersey: Blackwell Publishing. 63-103. 
Froehlich, J. (1988). German videos with German subtitles: A new approach to listening comprehension development, Die Unterrichtspraxis /Teaching German, 21(2):199-203.

Garza, T. J. (1991). Evaluating the use of captioned video materials in advanced foreign language learning. Foreign Language Annals, 24(3): 239-258.

Gass, S. M. (1997). Input, interaction and the second language learner, New Jersey: Lawrence Erlbaum Associates.

Gass, S. M, Mackey, A. (2005). Second Language Research: Methodology and Design, New Jersey: Lawrence Erlbaum Associates.

Gibson, E. J, Levin, H. (1975). The psychology of reading. Cambridge: MIT Press.

Gillespie, J. (1981). The role of television as an aid in foreign language teaching, Chicago: Language Learning Laboratory, University of Illinois.

Goldman, M, Goldman, S. (1988). Reading with closed captioned TV, Journal of Reading, 31(5): 458-461.

Goulden, R, Nation, P, Read J. (1990). How large can a receptive vocabulary be? Applied Linguistics, 11: 341-363.

Grgurović, M, Hegelheimer, V. (2007). Help options and multimedia listening: Students' use of subtitles and the transcript, Language Learning \& Technology, 11(1): 45-66.

Grimmer, C. (1992). Supertext English language subtitles: A boon for English language learners. EA Journal, 10(1): 6675.
Irujo, S. (1986a). Don't put your leg in your mouth: Transfer in the acquisition of idioms in a second language, TESOL Quarterly, 20: 287-304.

Irujo, S. (1986b). A piece of cake: Learning and teaching idioms, English Language Teaching, 40: 236-242.

Lewis, M.S, Jackson, D.W. (2001). Television literacy: Comprehension of program content using closed captions for the deaf. Journal of Deaf Studies and Deaf Education, 6: 43-53.

Koskinen, P, Wilson, R.M, Gambrell, L.B, Jensema, C. (1996). Using closed Captioned television to enhance reading skills of learning disabled students, National Reading Conference Yearbook, 35: 61-65.

Laufer, B. (2000). Avoidance of idioms in a second language: The effect of L1-L2 degree of similarity. Studia Linguistica, 52:186-196.

Liontas, J.I. (2001). That's All Greek to Me! The comprehension and interpretation of modern Greek phrasal idioms. The Reading Matrix: An International Online Journal, 1 (1): 1-32.

Long, M.H. (1996). The role of linguistic environment in second language acquisition. In W. C. Ritchie and T. K. Bhatia, (Eds.), The Handbook of second language acquisition, San Diego: Academic Press. 413-468.

Markham, P.L, (1993). Captioned television videotapes: Effects of visual support on second language comprehension, Journal of Educational Technology Systems, 21(3):183-191.

Markham, P.L. (2001). The influence of culture-specific background knowledge and captions on second language 
comprehension, Journal of Educational Technology Systems, 29(4):331-343.

Markham, P.L, Peter, L. (2003). The influence of English language and Spanish language captions on foreign language listening/reading comprehension, Journal of Educational Technology Systems, 31 (3):331-341.

McCarthy, M, O'Keeffe, A, Walsh, S. (2010). Vocabulary matrix: Understanding, learning, teaching, ELT Journal, 64(2): 243246.

McGavigan, P. (2009). The acquisition of fixed idioms in Greek learners of English as a foreign language. Unpublished doctoral dissertation in English by Research, Swansea University, Wales.

Milton, J. (2009). Measuring second language vocabulary acquisition, Bristol: Multilingual Matters.

Nagata, N. (1993). Intelligent computer feedback for second language instruction, The Modern Language Journal, 77: 330339.

Neuman, S. B., Koskinen, P. (1992). Captioned television as comprehensible input: Effects of incidental word learning from context for language minority students. Reading Research Quarterly, 27: 94-106.

Parks, C. (1986). A manual for closedcaptioned television in ESOL instruction, Upper Marlboro, Maryland: Prince George's County Public Schools.

Pica, T. (1994). Research on negotiation: What does it reveal about second-language Learning conditions, processes, and outcomes?, Journal of Language Learning, 44(3): 493- 527.
Pujola, J.T. (2002). Calling for help: Researching language learning strategies using help facilities in a web-based multimedia program, Journal of Recall, 14(2): 235-262.

Schmidt, R. (1990). The role of consciousness in second language learning, Applied Linguistics, 11(2): 129158.

Schmidt, R. (1993). Awareness and second language acquisition, Annual Review of Applied Linguistics, 13: 206-226.

Schmidt, R. (1994). Implicit learning and the cognitive unconscious: of artificial grammars and SLA. In N. Ellis (Ed.), Implicit and explicit learning of languages, London: Academic Press, 165-209.

Schmidt, R. (1995). Consciousness and foreign language learning: A tutorial on the role of attention and awareness, In $\mathrm{R}$. Schmidt (Ed.), Attention and awareness in foreign language teaching and learning, Honolulu: University of Hawai'i at Mānoa, 1-46.

Schmidt, R. (2001). Attention, In P. Robinson (Ed.), Cognition and second language instruction, Cambridge: Cambridge University Press, 3-32.

Seidl, J, McMordie, W. (1978). English idioms and how to use them. Oxford: Oxford University Press.

Smith, B. (2004). Computer-mediated negotiated interaction and lexical acquisition, Studies in Second Language Acquisition, 26(3): 365-398.

Guillory, H.G. (1998). The effects of key word captions to authentic French video on learner comprehension, CALICO Journal, 15(1-3): 89-108. 
Vanderplank, R. (1988). The value of teletext sub-titles in language learning, English Language Teaching Journal, 42(4): 272-281.

Vanderplank, R. (1990). Paying attention to the words: Practical and theoretical problems in watching television programmes with Uni-Lingual (CEEFAX) sub-titles. System,18(2): 221-234.

Welles, E.B. (2004). Foreign language enrollments in United States institutions of higher education, ADFL Bulletin, 35(2-3): 413-419.

Whitehurst, G.J, Lonigan, C.J. (1998). Child development and emergent literacy, Child Development, 69(3): 848-877.

Zarei, A, Koosha, M. (2003). Patterns of the Iranian advanced learners' problems with English collocations: A focus on lexical collocations, Iranian Journal of Applied Linguistics, 6(1): 137-169.
How to cite this article: Saeed Ketabi, Ali Sadeghi, The Effects of Captioned Slides on Learning of English Idiomatic Expressions among EFL Intermediate Learners. International Journal of Advanced Studies in Humanities and Social Science, 2020, 9(1), 1-20. http://www.ijashss.com/article 105605.html
How to
on Lear
Internat
$9(1), 1-20$ 